\title{
KOMPARASI ALGORITMA C4.5 BERBASIS PSO DAN GA UNTUK DIAGNOSA PENYAKIT STROKE
}

\author{
Ramdhan Saepul Rohman ${ }^{1}$, Rizal Amegia Saputra ${ }^{2}$, Dasya Arif Firmansaha ${ }^{3}$
}

Page | 155

\author{
1,2,3 Fakultas Teknologi Informasi, Universitas Bina Sarana Informatika \\ Jl. Cemerlang No. 8 Sukakarya Sukabumi, Jawa Barat \\ ${ }^{1}$ ramdhan.rpe@bsi.ac.id, ${ }^{2}$ rizal.rga@bsi.ac.id, ${ }^{3}$ dasya.daf@bsi.ac.id
}

\begin{abstract}
Abstrak-Stroke merupakan gangguan fungsi otak baik lokal maupun menyeluruh yang disebabkan karena pasokan darah ke otak terganggu yang terjadi secara cepat dan berlangsung lebih dari 24 jam atau berakhir dengan kematian. Stroke Merupakan 1 dari 10 jenis penyakit yang paling mematikan di Indonesia. Hal ini berdasarkan pada data yang dikumpulkan dari sampel yang mewakili Indonesia, meliputi 41.590 kematian sepanjang 2014 dan pada semua kematian itu dilakukan autopsi verbal, sesuai pedoman Badan Kesehatan Dunia. Pentingnya mengetahui gejala sejak dini merupakan langkah awal dalam pencegahan terjadinya stroke. Maka itu, dilakukan penelitian untuk menganalisa data terkait dengan penyebab stroke. Adapun atribut yang terlibat dalam penyebab terjadinya stroke yakni, usia, jenis kelamin, kadar glukosa, riwayat penyakit jantung, hipertensi, tipe pekerjaan, tipe tempat tinggal, status merokok, index masa tubuh dan status pernikahan. Diperlukan suatu algoritma tertentu untuk mengklasifikasikan semua atribut tersebut. C45 merupakan Algoritma yang paling banyak digunakan, dalam kasus ini akurasi dari algoritma C4.5 sebesar $99.07 \%$. Selanjutnya Algoritma C4.5 dioptimasi dengan menggunakan Particle Swarm Optimization sehingga memperoleh akurasi sebesar $\mathbf{9 9 . 2 8} \%$ dan Algoritma C4.5 juga dioptimasi dengan menggunakan Genetic Algorithm sehingga memperoleh akurasi sebesar $99.38 \%$.
\end{abstract}

Kata Kunci-Stroke, C4.5, Algoritma C4.5, Particle Swarm Optimization, Genetic Algorithm.

Abstract-Stroke is a disorder of brain function both locally and comprehensively due to a disrupted blood supply to the brain that occurs quickly and lasts more than 24 hours or ends with death. Stroke is one of the 10 most deadly diseases in Indonesia. This is based on data collected from samples representing Indonesia, covering 41,590 deaths throughout 2014 and in all deaths a verbal autopsy was carried out, according to World Health Organization guidelines. The importance of knowing symptoms early on is the first step in preventing stroke. Therefore, research was conducted to analyze data related to the cause of stroke. The attributes involved in the cause of stroke are age, sex, glucose level, history of heart disease, hypertension, type of work, type of residence, smoking status, body mass index and marital status. A certain algorithm is needed to classify all of these attributes. C45 is the most widely used algorithm, in this case the accuracy of the C4.5 algorithm is $99.07 \%$. Furthermore, the C4.5 Algorithm was optimized using Particle Swarm Optimization to obtain an accuracy of $99.28 \%$ and the $\mathbf{C 4 . 5}$ Algorithm was also optimized by using the Genetic Algorithm to obtain an accuracy of $\mathbf{9 9 . 3 8 \%}$.

Keywords-Stroke, C4.5, Algoritma C4.5, Particle Swarm Optimization, Genetic Algorithm.

\section{PENDAHULUAN}

Pentingnya mengetahui gejala penyakit merupakan langkah awal dalam mengantisipasi timbulnya suatu penyakit yang dapat membahayakan kesehatan dan bahkan menyebabkan kematian.

Stroke merupakan gangguan fungsi otak baik lokal maupun menyeluruh yang disebabkan karena pasokan darah ke otak terganggu yang terjadi secara cepat dan berlangsung lebih dari 24 jam atau berakhir dengan kematian[1].

Stroke Merupakan 1 dari 10 jenis penyakit yang paling mematikan di Indonesia. Hal ini berdasarkan pada data yang dikumpulkan dari sampel yang mewakili Indonesia, meliputi 41.590 kematian sepanjang 2014 dan pada semua kematian itu dilakukan autopsi verbal, sesuai pedoman Badan Kesehatan Dunia (WHO) secara real time oleh dokter dan petugas terlatih [2].

Stroke menjadi salah satu penyakit yang paling banyak diderita oleh masyarakat Indonesia dan juga menjadi salah satu penyebab kematian tertinggi di Indonesia pada urutan pertama disusul oleh diabetes dan hipertensi[3].

Telah banyak penelitian yang sudah dilakukan diantaranya: Menurut jurnal Sigit Abdillah yang berjudul Penerapan Algoritma Decision Tree C4.5 Untuk Diagnosa Penyakit Stroke Dengan Klasifikasi Data Mining Pada Rumah Sakit Santa Maria Pemalang, mengemukakan bahwa untuk studi kasus penyakit stroke dapat memanfaatkan teknik klasifikasi data 
mining dengan algoritma C4.5 sebagai klasifikasi stroke atau non-stroke. Dari metode klasifikasi data mining dengan algoritma $\mathrm{C} 4.5$ dan pengaplikasian pohon keputusan yang membentuk aturan tersebut terdapat akurasi pada data training yang berjumlah 130 dari 156 data pasien sebesar 82,31\% sedangkan akurasi pada data testing yang berjumlah 26 dari 156 data pasien sebesar 76,92\%. Perhitungan keduanya menggunakanconfusion matrix. Menurut jurnal Vina Adelina, Dian Eka Ratnawati, M. Ali Fauzi dalam penelitiannya menentukan tingkat resiko stroke menggunakan metode Metode GA-Fuzzy Tsukamoto dengan tingkat akurasi yang didapatkan sebesar 86.66\%. Menurut jurnal Jeena R S dan Sukesh Kumar dalam penelitiannya memprediksi stroke menggunakan metode SVM dan akurasi yang diperoleh sebesar 90\% dengan menggunakan 12 atribut berupa Usia, Jenis Kelamin, gejala Berjalan, Fibrilasi Atrium, Defisit wajah, Lengan / Tangan defisit, Kaki / Kaki defisit, Infark terlihat pada CT, Dyphasi, Hemianopia, Gangguan Visuospatial, tanda Cerebellar.

Penelitian ini bertujuan untuk menerapkan algoritma C4.5 sebagai algoritma data mining yang paling banyak digunakan serta komparasi antara optimasi Genetic Algorithm (GA) dan optimasi Particle Swarm Optimization (PSO) dalam memprediksi terjadinya penyakit stroke.

\section{A. Jenis Penelitian}

\section{Metode Penelitian}

Dalam Penelitian ini dilakukan dua pendekatan utama penelitian, yaitu pendekatan kualitatif dan pendekatan kuantitatif. Pendekatan Kualitatif digunakan untuk menganalisa kajian literatur yang berkenaan dengan variable-variabel yang digunakan dalam pengumpulan data[5].

Sedangkan pendekatatan kuantitif merupakan metode penelitian yang digunakan untuk meneliti pada populasi atau sampel tertentu, pengumpulan data menggunakan instrumen penelitian dan analisis data bersifat statistik atau kuantitatif dengan tujuan untuk menguji hipotesis yang telah ditetapkan[6].

\section{B. Metode Pengumpulan Data}

Pada tahap ini metode pengumpulan data dibagi menjadi dua sumber data yakni data primer dan data sekunder. Data primer yaitu data yang dikumpulkan dari sumbernya langsung, sedangkan data sekunder yaitu data yang dikumpulkan dari peneliti sebelumnya. Dalam penelitian ini metode pengumpulan data untuk mendapatkan sumber data yang digunakan adalah metode pengumpulan data sekunder. Data utama diperoleh dari kaggle dataset repository yang dapat diperoleh melalui alamat web https://www.kaggle.com/asaumya/healthcare-datasetstroke-data sedangkan data pendukung didapatkan dari buku, jurnal dan publikasi lainnya

\section{Validasi Data}

Data dalam penelitian ini diambil dari Kaggle Dataset yang terdiri dari 10 atribut predictor dan 1 atribut hasil. Pada dataset tersebut akan dilakukan validasi data dengan menghilangkan data missing value. Data yang didapat dari Kaggle Dataset sebanyak 43401 record, dari data tersebut terdapat data missing value sebanyak 14335 record. Kemudian data missing value tersebut akan dihilangkan agar data menjadi valid sehingga data yang diolah tanpa missing value adalah sebanyak 29066 record setelah itu dilakukan remove duplicate sehingga data yang diperoleh sebanyak 2906. Pengolahan data juga dapat berupa konversi nilai agar mempermudah pembentukan model

TABEL I

ATRIBUT DAN NILAI KATEGORI DALAM MEMPREDIKSI PENYAKIT STROKE

\begin{tabular}{|c|c|c|}
\hline Atribut & Nilai & Sumber \\
\hline \multirow{8}{*}{ AGE } & $<15$ & \multirow{8}{*}{$\begin{array}{c}\text { (Kementerian Kesehatan } \\
\text { RI, 2014) }\end{array}$} \\
\hline & $15-24$ & \\
\hline & $25-34$ & \\
\hline & $35-44$ & \\
\hline & $45-54$ & \\
\hline & $55-64$ & \\
\hline & $65-74$ & \\
\hline & $>75$ & \\
\hline \multirow{2}{*}{ GENDER } & FEMALE & \multirow{2}{*}{ Kaggel Dataset } \\
\hline & MALE & \\
\hline \multirow{2}{*}{ HYPERTENSION } & 0 & \multirow[t]{2}{*}{ Kaggle Dataset } \\
\hline & 1 & \\
\hline \multirow{2}{*}{ HEART DISEASE } & 0 & \multirow[t]{2}{*}{ Kaggle Dataset } \\
\hline & 1 & \\
\hline \multirow{2}{*}{ EVER MARRIED } & YES & \multirow{2}{*}{ Kaggle Dataset } \\
\hline & NO & \\
\hline \multirow{5}{*}{ WORK TYPE } & Children & \multirow{5}{*}{ Kaggle Dataset } \\
\hline & Private & \\
\hline & Self Employed & \\
\hline & Govt_job & \\
\hline & Never Work & \\
\hline \multirow{2}{*}{ RESIDENCE TYPE } & Urban & \multirow[t]{2}{*}{ Kaggle Dataset } \\
\hline & Rural & \\
\hline \multirow{2}{*}{$\begin{array}{l}\text { AVG CLUCOSE } \\
\text { LEVEL (After Meal) }\end{array}$} & $<180 \mathrm{mg} / \mathrm{dl}$ & \multirow[t]{2}{*}{ (Noys, 2016) } \\
\hline & $>180 \mathrm{mg} / \mathrm{dl}$ & \\
\hline \multirow{3}{*}{ BMII } & $<30 \mathrm{Kg} / \mathrm{m}$ & \multirow{3}{*}{ (Quamila, 2017) } \\
\hline & $30 \mathrm{Kg} / \mathrm{m}$ & \\
\hline & $>30 \mathrm{Kg} / \mathrm{m}$ & \\
\hline \multirow{3}{*}{ SMOKING STATUS } & Formerly smoked & \multirow[t]{3}{*}{ Kaggle Dataset } \\
\hline & Smoked & \\
\hline & Never Smoked & \\
\hline
\end{tabular}

Berikut merupakan deskripsi dari atribut diatas :

\section{Age/Umur}

Mencakup usia dari usia pasien, menurut data kementerian kesehatan batasan usia yang berpotensi mengidap penyakit stroke diantaranya :
a. $15-24$
b. $25-34$
c. $35-44$
d. 45-54
e. $35-44$
f. 55-64
g. $65-74$ 
h. $>75$

2. Gender/ Jenis kelamin Mencakup jenis kelamin dari pasien dengan kategori Male (Laki-laki) dan Female (Perempuan)

3. Hypertension

Salah satu atribut yang mengindikasikan apakah pasien yang bersangkutan memiliki riwayat penyakit hipertensi/ darah tinggi ataukah tidak

4. Heart Disease

Salah satu atribut yang mengindikasikan apakah pasien yang bersangkutan memiliki riwayat penyakit penyakit jantung ataukah tidak

5. EverMarried

Salah satu atribut yang mengindikasikan apakah pasien yang bersangkutan pernah menikah ataukah tidak

6. Work Type

Salah satu atribut yang mengindikasikan type pekerjaan dari pasien yang merupakan salah satu penyebab stres yang berpotensi terjadinya penyakit stroke diantaranya:
a. Children (Anak-anak)
b. Private (Pribadi)
c. Self Employed (Bekerja Sendiri)
d. Govt_job (Pekerja Pemerintahan)
e. Never Work (Tidak Bekerja)

\section{Residence Type}

Mencakup tempat tinggal dari pasien yang meliputi Urban (Perkotaan) dan Rural (Pedesaan)

8. AVG Glucose Level

Mencakup rata-rata tingkat glukosa (Kadar gula dalam darah) yang dapat menyebabkan timbulnya penyakit stroke. pada dataset yang diteliti ini mencakup "measured after meal" (Diukur setelah makan).

Kadar glukosa yang berpotensi mengakibatkan stroke pada pasien, diantaranya adalah pasien dengan kadar gula berlebih (hiperglikemia). Berikut kisaran kadar gula darah normal pada tubuh (Noya , 2016):

a. Sebelum makan: sekitar $70-130 \mathrm{mg} / \mathrm{dL}$

b. Dua jam setelah makan: kurang dari $180 \mathrm{mg} / \mathrm{dL}$

c. Setelah tidak makan (puasa) selama setidaknya delapan jam: kurang dari $100 \mathrm{mg} / \mathrm{dL}$

d. Menjelang tidur: $100-140 \mathrm{mg} / \mathrm{dL}$

Menjaga kadar gula darah agar dalam angka normal sangat penting. Gula darah terlalu rendah (hipoglikemia) atau tinggi (hiperglikemia) bisa berdampak negatif pada tubuh. Jika gula darah
Anda di bawah $70 \mathrm{mg} / \mathrm{dL}$ maka Anda mengalami hipoglikemia. Anda dikatakan mengalami hiperglikemia jika kadar gula darah Anda lebih dari $200 \mathrm{mg} / \mathrm{dL}$.

\section{BMI (Body Mass Index)}

Obesitas dengan tingkat BMI > $30 \mathrm{Kg} / \mathrm{m}$ Sangat berpotensi mengalami resiko stroke secara independen ( $\mathrm{Li}$, et al., 2015)

Didefinisikan sebagai indeks massa tubuh (BMI) 30 atau lebih, obesitas sendiri merupakan faktor risiko untuk stroke, terlepas apakah seseorang memiliki faktor risiko lain seperti tekanan darah tinggi atau diabetes (Samiadi, 2017). Indeks massa tubuh alias BMI membandingkan berat badan dengan tinggi badan, dihitung dengan membagi berat badan dalam kilogram dengan tinggi badan dalam meter kuadrat ( Quamila, 2017).

$$
\mathrm{BMI}=\frac{\text { (weight in kilograms })}{\text { height in meters }^{2}}
$$

10. Smoking Status

Salah satu atribut yang mengindikasikan status perokok/bukan perokok dari pasien dengan kategori :
a. Formerly smoked (Sebelumnya merokok)
b. Smoked (Merokok)
c. Never Smoked (Tidak pernah merokok)

11. Stroke

Atribut ini merupakan atribut predictor atau penentu dengan kategori Suffered stroke (Menderita Stroke) dan No Stroke (Tidak Stroke)

\section{Kerangka Pemikiran}

Penelitian ini terdiri dari beberapa tahapan seperti terlihat pada gambar kerangka pemikiran 2.9. Permasalahan pada penelitian ini adalah belum begitu banyak penggunaan metode dalam memprediksi penyakit stroke serta belum dilakukannya komparasi algoritma $\mathrm{C} 4.5$ berbasis PSO dan C4.5 berbasis GA

Atas dasar alasan tersebut diatas, maka dilakukan penelitian menggunakan metode klasifikasi algoritma C4.5 berbasis PSO (Particle Swarm Optimization) dan juga C4.5 berbasis Genetic Algorithm dalam memprediksi penyakit stroke. Pengujian metode dilakukan dengan cara confusion matrix dan kurva ROC. Untuk mengembangkan aplikasi berdasarkan metode, digunakan tools RapidMiner studio serta didukung dengan penggunaan pembuatan aplikasi berbasis web. Berikut dibawah ini kerangka pemikiran yang penulis buat untuk penelitian ini: 


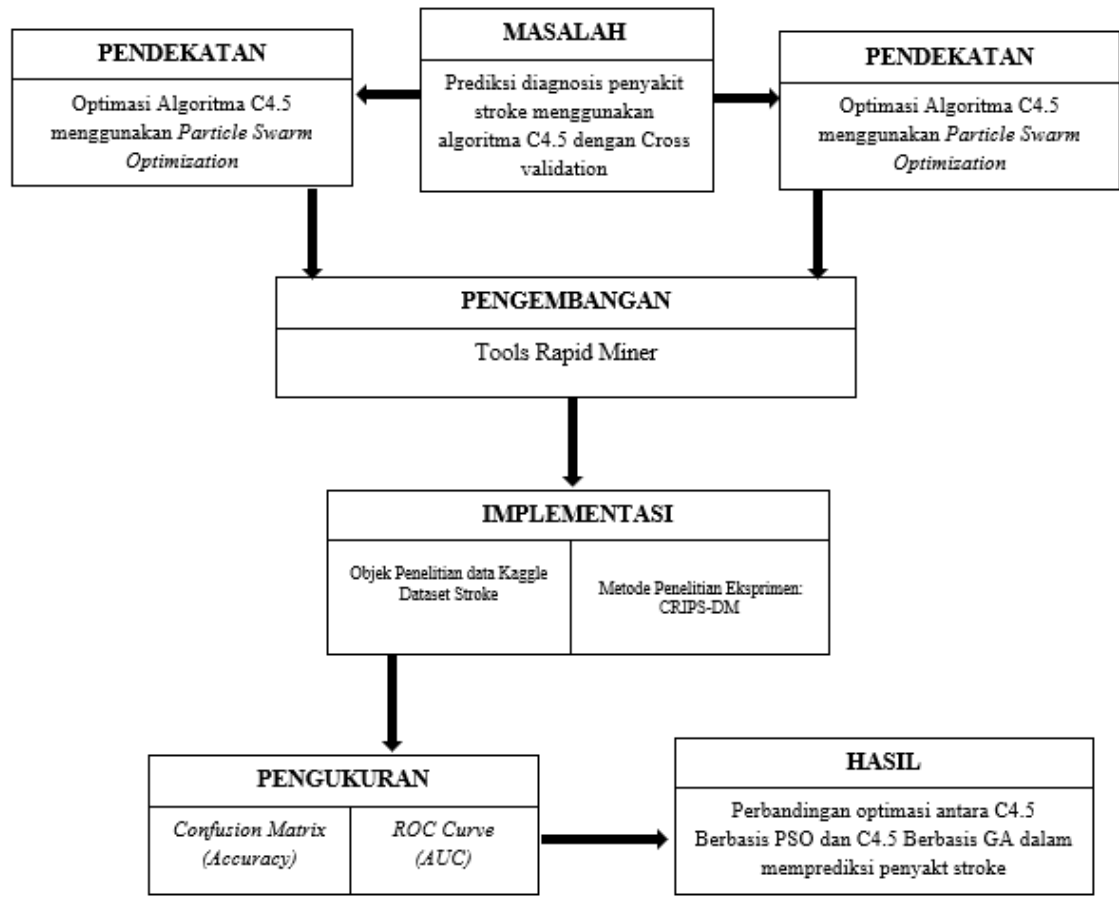

\section{E. Data Mining}

Data mining adalah suatu disiplin ilmu yang bertujuan untuk menemukan, menggali atau menambahkan pengetahuan dari data atau informasi yang kita miliki[7][8].Menurut Gartner Group menyebutkan bahwa Data Miningadalah proses menelusuri pengetahuan baru, pola dan tren yang dipilih dari jumlah data yang besar yang disimpan dalam repositori atau tempat penyimpanan dengan menggunakan teknik pengenalan pola serta statistik dan tehnik matematika [8].

\section{F. Algoritma C4.5}

Algoritma C4.5 merupakan salah satu solusi pemecahan kasus yang sering digunakan dalam pemecahan masalah pada teknik klasifikasi[9]. Pemilihan atribut sebagai simpul, baik simpul akar (root) atau simpul internal didasarkan pada nilai Gain tertinggi dari atribut-atribut yang ada. Penghitungan nilai Gain digunakan rumus seperti dalam Persamaan 1.

$\operatorname{Gain}(S, A)=\operatorname{Entropy}(S)-\sum_{i=1}^{n} \frac{\mid S_{i} \|}{|S|} * \operatorname{Entropy}\left(S_{i}\right)$

$S$ : Himpunan kasus

$A$ : Atribut

$n$ : Jumlah partisi himpunan atribut A

$\left|S_{i}\right|:$ Jumlah kasus pada partisi ke- i

$|S|$ : Jumlah kasus dalam $\mathrm{S}$

Untuk menghitung nilai Entropy dapat dilihat pada Persamaan 2

$$
\text { Entropy }(S)=\sum_{i=1}^{n}-p i * \log _{2}(p i)
$$

$n$ : Jumlah partisi $S$

pi : Proporsi dari $S_{i}$ terhadap $S$

\section{G. Particle Swarm Optimization (PSO)}

Teknik perhitungan evolusi yang dikembangkan oleh Kennedy dan Eberhart tahun 1995, PSO dikembangkan dari kecerdasan berkelompok dan didasarkan pada penelitian perilaku gerakan kawanan burung dan ikan. Sementara mencari makanan, burung-burung yang baik tersebar atau pergi bersama-sama sebelum mereka menemukan tempat di mana mereka dapat menemukan makanan. Sementara burung mencari makanan dari satu tempat ke tempat[10].

Secara garis besar, algoritma PSO dapat dijabarkan dalam rumus berikut :

$v i=w * v i+r$ and $(0,1) * c 1 *(x p B$ est $-x i)$

$$
+r \text { and }(0,1) * c 2 *(x g B \text { est }-x i)
$$

dimana $v i$ merupakan kecepatan dari partikel ke-i, $w$ merupakan parameter inertia weight, $\quad c 1$ merupakan parameter cognitive factor, $\quad c \quad 1$ merupakan parameter social factor, $x i$ adalah koordinat posisi dari partikel ke-i yang melambangkan kandidat solusi dari suatu permasalahan, $x p$ est adalah koordinat posisi dari pBest, $x g$ est adalah koordinat posisi dari gBest.

Modifikasi kecepatan dan posisi tiap partikel dapat dihitung menggunakan kecepatan saat ini dan jarak pbest $_{i, d}$ ke gbest $_{d}$ seperti ditunjukan pada persamaan berikut:

$v_{i, m}=w \cdot v_{i, m}+c_{1} * R *\left(\right.$ pbest $\left._{i, m}-x_{i, m}\right)+c_{2} * R *$ $\left(\right.$ gbest $\left._{m}-x_{i, m}\right)$

$x_{i d}=x_{i, m}+v_{i, m}$

Dimana:

n : jumlah partikel dalam kelompok

d : dimensi

$v_{i, m} \quad$ : kecepatan partikel ke-i pada iterasi ke-i 
w : faktor bobot inersia

$c_{1}, c_{2}:$ konstanta akselerasi (learning rate)

$\mathrm{R}$ : bilangan random (0-1)

$x_{i, d} \quad$ : posisi saat ini dari partikel ke-i pada iterasi ke-

$\mathrm{i}$

pbest $_{i}:$ posisi terbaik sebelumnya dari partikel ke-i

gbest : partikel terbaik diantara semua partikel dalam

satu kelompok atau populasi.

\section{H. Genetic Algorithm(GA)}

Genetic Algorithm atau Algoritma Genetika adalah salah satu tipe algoritme evolusi yang populer dan sudah banyak digunakan untuk masalah-masalah kompleks pada berbagai bidang. Algoritme Genetika bekerja dengan sebuah populasi yang terdiri dari suatu individu-individu yang dimana masing-masing dapat merepresentasikan sebuah solusi yang mungkin bagi persoalan yang ada[4].

Berikut merupakan parameter dan siklus dari algoritma genetika[4]:

a. Parameter Algoritma Genetika

Dalam Algoritme Genetika terdapat beberapa parameter antara lain:

1. Ukuran Populasi (Popsize)

2. Tingkat pindah silang atau Crossover rate (Cr)

3. Tingkat Mutasi atau Mutation Rate (Mr)

4. Kondisi berhenti atau stop

b. Siklus dalam Algoritme Genetika yaitu :

1. Inisialisasi

2. Reproduksi (Crossover, Mutasi)

3. Evaluasi (Fitness \& Offspring)

4. Populasi generasi selanjutnya
Pendekatan yang diambil oleh algoritma ini adalah dengan menggabungkan secara acak berbagai pilihan solusi terbaik di dalam suatu kumpulan untuk mendapatkan generasi solusi terbaik berikutnya yaitu pada suatu kondisi yang memaksimalkan kecocokannya atau lazim disebut fitness[11].

\section{PEMBAHASAN}

Penelitian ini bertujuan untuk menerapkan dan membandingkan Particle Swarm Optimizing dan Genetic Algorithm dalam meningkatkan tingkat akurasi prediksi penyakit stroke dengan menggunakan metode C4.5. Hasil dari penelitian ini sendiri berupa hasil pengolahan data kualitatif dan kuantitatif dengan perhitungan berdasarkan model yang diusulkan. Penelitian dilakukan pada sebuah dataset yang sudah tersedia yang bersifat publik. Eksperimen dan pengujian dalam penelitian ini dilakukan dengan menggunakan metode C4.5 tanpa PSO atau GA dan metode menggunakan PSO atau GA.

1. Eksperimen dan pengujian model C4.5

Pengelolaan data menggunakan model C4.5 dilakukan pada dataset yang terdiri dari 11 atribut yang merupakan atribut dari diagnosis penyakit stroke dan class yang merupakan hasil akhir prediksi.

Model dari algoritma C4.5 yaitu berupa pohon keputusan, agar lebih mudah dalam membuat pohon keputusan, langkah pertama adalah menghitung jumlah class yang berpotensi terkena penyakit stroke dan tidak stroke dari masing-masing class berdasarkan atribut yang telah ditentukan dengan menggunakan data training.

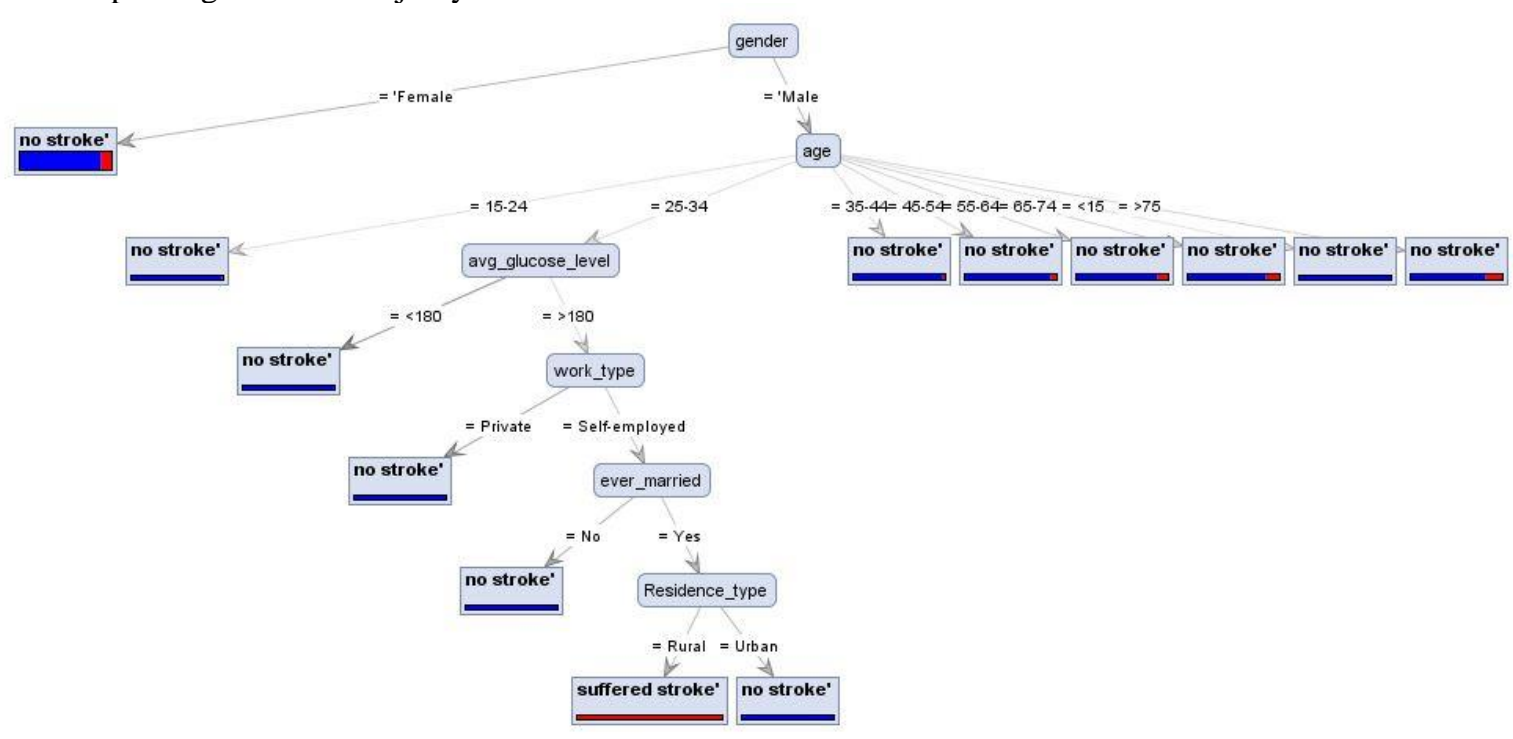

Gbr 2. Pohon Keputusan Klasifikasi Penyakit Stoke Menggunakan Algoritma C4.5 


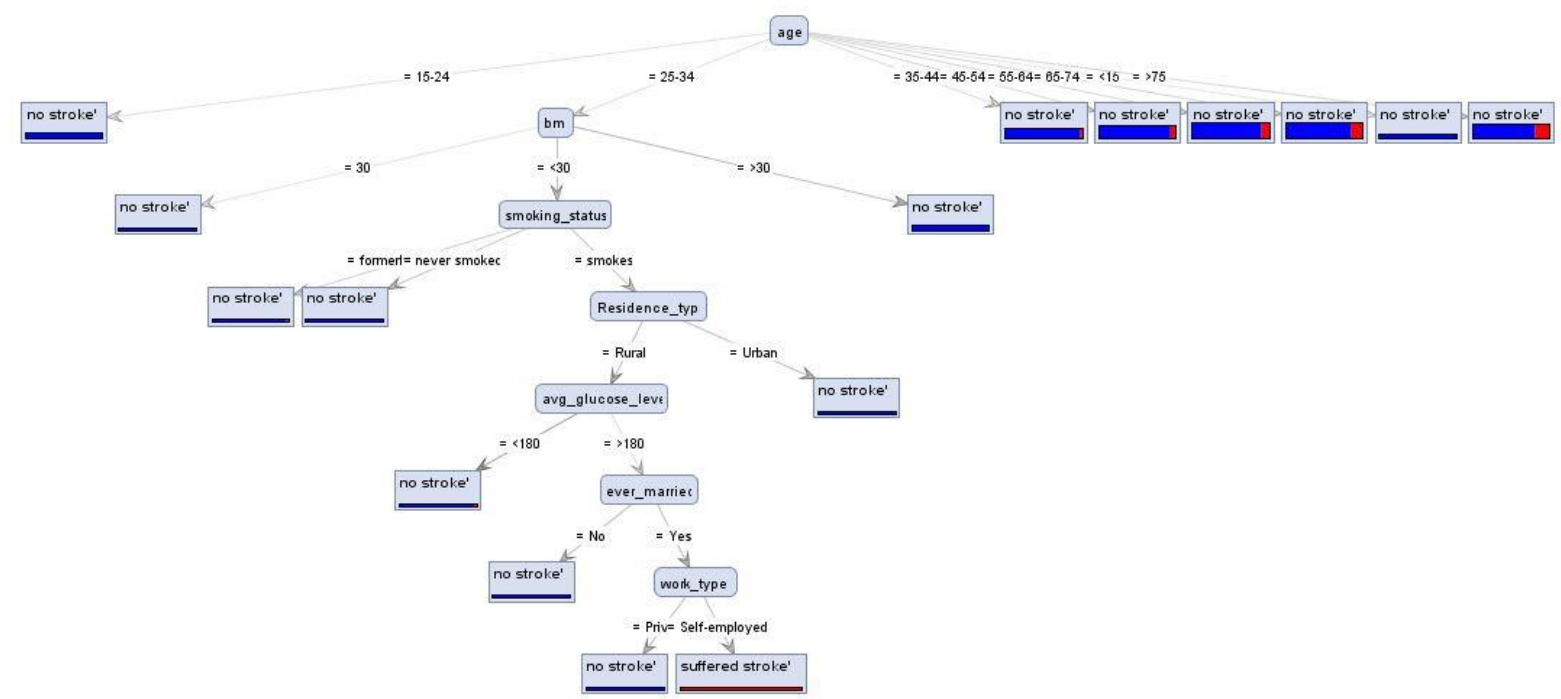

Gbr 3. Pohon Keputusan Klasifikasi Penyakit Stoke PSO-C4.5

Dari pohon keputusan tersebut maka diperoleh aturan-aturan atau rule sebagai berikut: $\mathrm{R} 1:$ if Age $=15-24$ then class = no Stroke

$\mathrm{R} 2$ : if Age $=25-34$ and $\mathrm{bmi}=30$ then class $=$ no stroke

R3 : if Age = 25-34 and bmi $<30$ and smoking status $=$ fomrmely smoking then class $=$ no stroke

R4 : if Age = 25-34 and bmi $<30$ and smoking status $=$ Never smoked then class $=$ no stroke

R5 : if Age $=25-34$ and smoking status $=$ smokes and Residence Type $=$ Rural and Avg Glukosa $<=180$ then class no stroke

R6 : if Age $=25-34$ and Avg Glukosa $>=180$ and ever married $=$ No then class no stroke

R6 : if Age $=25-34$ and ever Married $=$ Yes and Work Type $=$ Private then class no stroke

R7 : if Age $=25-34$ and Work Type $=$ Self Employed then class Suffered Stroke

R8 : if Age = 25-34 and Residence Type = Urban then class No Stroke

R9 : if Age $=25-34$ and bmi $=>30$ then class No Stroke

$\mathrm{R} 10:$ if Age $=35-44$ then class $=$ no stroke

$\mathrm{R} 11:$ if Age $=45-54$ then class $=$ no stroke

$\mathrm{R} 12:$ if Age $=55-64$ then class $=$ no stroke

$\mathrm{R} 13:$ if Age $=65-74$ then class $=$ no stroke

R14 : if Age $=<15$ then class $=$ no stroke

$\mathrm{R} 15:$ if Age $=>75$ then class $=$ no stroke

Terdapat 16 rule yang dihasilkan dari pohon keputusan algoritma klasifikasi C4.5, dengan jumlah class no stroke sebanyak 15 rule dan 1 rule untuk class Suffered Strokes. Sedangkan atribut yang terseleksi dari 11 atribut menjadi 9 atribut yang terdiri dari Age, Heart desease, Ever Married, work Type, Avg Glukose Level, BMI, Residence Status, Smoking Status, Stroke.

2. Komparasi Model Algoritma C4.5 dengan Algoritma C4.5 - PSO dan C4.5 - GA
TABLE II

PERBANDINGAN AKURASI DAN NILAI AUC

\begin{tabular}{|l|l|l|}
\hline & Accuracy & AUC \\
\hline C4.5 & $89,93 \%$ & 0.610 \\
\hline C4.5-PSO & $91,63 \%$ & 0.500 \\
\hline C4.5-GA & $92,02 \%$ & 0.500 \\
\hline
\end{tabular}

Hasil dari pengujian diatas menjelaskan bahwa pengujian C4.5 menjadi lebih baik ketika menggunakan optimasi Particle Swarm Optimization dan Genetik Algorithm. Terbukti dengan menggunakan C4.5 berbasis PSO maka akurasi yang diperoleh sebesar $91,63 \%$ dibanding dengan $\mathrm{C} 4.5$ saja yang hanya mendapatkan 89,93\%. Namun meskipun demikian tingkat akurasi yang didapatkan jauh lebih tinggi menggunakan GA dibanding dengan menggunakan PSO dengan tingkat akurasi sebesar $92,02 \%$

\section{Pengembangan Aplikasi Model dari Algoritma C4.5}

Berdasarkan hasil eksperimen didapatkan model terbaik dari metode algoritma $\mathrm{C} 4.5$ dan algoritma C4.5 dan Particle Swarm Optimization, yang dikembangkan menjadi sebuah aplikasi.

Berikut merupakan rancangan antarmuka aplikasi dalam memprediksi penyakit stroke : 


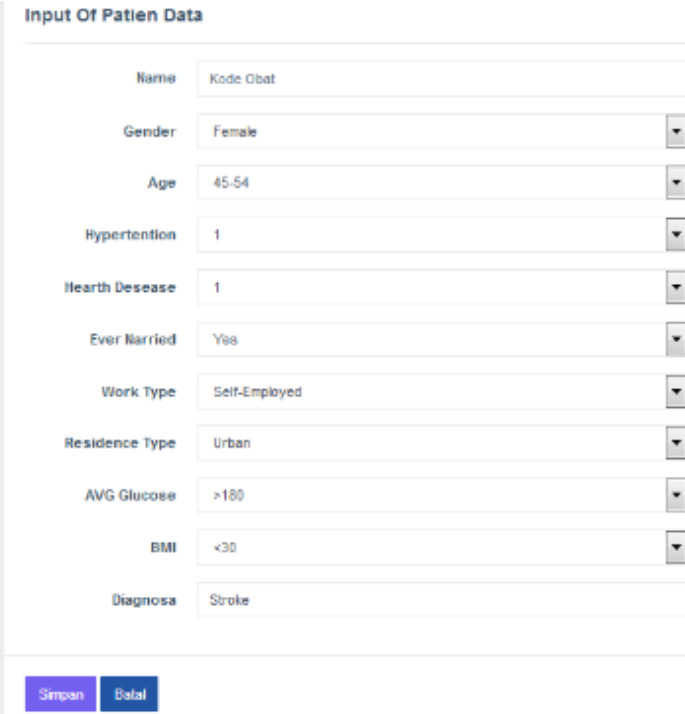

Gbr 4 Pengujian Aplikasi Model Algoritma C4.5 dan Particle Swarm Optimization

\section{IV.PENUTUP}

Dari pembahasan-pembahasan diatas dapat ditarik kesimpulan bahwa Penelitian dengan menerapkan particle swarm optimization dan Genetic Algorithm pada algoritma C4.5 dilakukan agar dapat dapat diketahui seberapa besar tingkat akurasi yang dihasilkan dalam mendiagnosa penyakit stroke.

Dalam menyeleksi atribut dibutuhkan suatu algoritma particle swarm optimization pada $\mathrm{C} 4.5$, untuk proses pembelajarannya dieksperimenkan pada Rapidminer. Sedangkan proses pengujiannya menggunakan Accuracy dan ROC Curve untuk melihat tingkat keakuratan prediksi diagnosis penyakit hepatitis. Atribut yang digunakan yaitu gender, age, hypertension, heart desease, ever married, work type, avg glukose level, bmi, residence status, smoking status, stroke.

Dari 11 atribut yang terdapat pada dataset kaggle, kemudian selanjutnya diseleksi menjadi hanya 10 atribut yang digunakan dalam menentukan prediksi penyakit hepatitis, atribut-atribut tersebut yaitu : gender, age, hypertension, heart desease, ever married, work type, avg glukose level, bmi, residence status, stroke.

Sehingga dapat disimpulkan bahwa penerapan teknik optimasi particle swarm optimization mampu menyeleksi atribut pada C4.5, sehingga menghasilkan tingkat akurasi diagnosis penyakit hepatitis yang lebih baik dibanding dengan menggunakan metode individual algoritma $\mathrm{C} 4.5$.

\section{REFERENSI}

[1] LF, N. (2013). Stroke Non Hemoragik Pada Laki-Laki Usia 65 Tahun . Medula, 1-9.

[2] Widowati, U. (2015, Mei 14). Berita Kesehatan : 10 Penyakit Paling Mematikan di Indonesia . Retrieved juni 29, 2018, from $\mathrm{CNN}$

Indonesia: https://www.cnnindonesia.com/gayahidup/20150513163407255-53129/10-penyakit-paling-mematikan-di-indonesia.

[3] Albirra, F. (2017, November 21). Kesehatan : Inilah Penyakit yang Paling Banyak Menyerang Masyarakat Indonesia. Retrieved Juni 29, 2018, from Jawa Pos: https://www.jawapos.com/kesehatan/21/11/2017/inilahpenyakit-yang-paling-banyak-menyerang-masyarakatindonesia

[4] Adelina, V., Ratnawati, D. E., \& Fauzi, M. (2018).Klasifikasi Tingkat Risiko Penyakit Stroke Menggunakan Metode GAFuzzy Tsukamoto . Jurnal Pengembangan Teknologi Informasi dan Ilmu Komputer, 3015-3021.

[5] Fauzi, A., \& Suharjo, B. (2016). Pengaruh Sumber Daya Finansial, Aset Tidak Berwujud dan Keunggulan Bersaing yang Berimplikasi Terhadap Kinerja Usaha Mikro, Kecil dan Menengah di Lombok NTB. Manajemen IKM, 151-158.

[6] Lestari , Y. A., \& Nuzula , N. F. (2017). Analisis pengaruh financial leverage dan operating leverage terhadap profitabilitas perusahaan. Jurnal Administrasi Bisnis, 1-10.

[7] Susanto, S., \& Suryadi, D. (2010). Pengantar Data Mining Menggali Pengetahuan dari Bongkahan Data.Yogyakarta: C.V ANDI OFFSET

[8] Saputra, R. A. (2014). Komparasi Algoritma Klasifikasi Data Mining Untuk Memprediksi Penyakit Tuberculosis (Tb): Studi Kasus Puskesmas Karawang Sukabumi. In Seminar Nasional Inovasi dan Tren (SNIT) (pp. 1-8).

[9] Nofriansyag, D \& Nurcahyo, G.W.(2015). Algoritma Data Mining Dan Pengujian.Yogyakarta. Deepublish.

[10] Ramdhani, L. S. (2016). Penerapan Particle Swarm Optimization (PSO) untuk Seleksi Atribut dalam Meningkatkan Akurasi Prediksi Diagnosis Penyakit Hepatitis dengan Metode Algoritma C4. 5. Swabumi, 4(1), 1-15.

[11] Nugroho, D. P. (2015). Optimasi Solusi Permasalahan Rute Kendaraan Dengan Pemerataan Beban Menggunakan Genetic Algorithm. Jurnal Penelitian Transportasi Multimoda, 1-10. 